Article

\title{
Formation of Secondary Organic Aerosols by Germicidal Ultraviolet Light
}

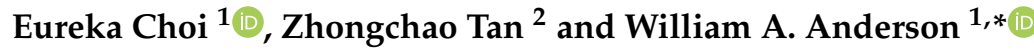 \\ 1 Department of Chemical Engineering, University of Waterloo, Waterloo, ON N2L 3G1, Canada; \\ e22choi@uwaterloo.ca \\ 2 Department of Mechanical and Mechatronics Engineering, University of Waterloo, Waterloo, ON N2L 3G1, \\ Canada; tanz@uwaterloo.ca \\ * Correspondence: wanderson@uwaterloo.ca; Tel.: +519-888-4567 (ext. 35011)
}

Received: 30 November 2018; Accepted: 27 January 2019; Published: 31 January 2019

\begin{abstract}
Ultraviolet (UV) light with a wavelength of $254 \mathrm{~nm}$ is known to be germicidal, and thus has been increasingly employed as a method of disinfection for indoor environments. Solar UV wavelengths ( 300 to $400 \mathrm{~nm}$ ) are known to initiate the formation of secondary organic aerosol (SOA) particles from the photo-oxidation of volatile organic compounds (VOC) in the atmosphere, but germicidal wavelengths have not been extensively studied for indoor environments. In this work, toluene was exposed to $254 \mathrm{~nm}$ UV light in a laboratory photoreactor while varying the conditions of the air, the duration of UV exposure, and the duration of post-UV time. The number of particles formed in the fine particulate matter (PM2.5) size range was measured, and significant levels of particle formation were observed for UV exposure periods of as short as $5 \mathrm{~min}$. The particle formation ranged from $2.4 \times 10^{6}$ particles $/ \mathrm{m}^{3}$ for 5 min of UV exposure, to $163.2 \times 10^{6}$ particles $/ \mathrm{m}^{3}$ for $15 \mathrm{~min}$ of UV exposure, for toluene concentrations in the range of 55 to $85 \mathrm{mg} / \mathrm{m}^{3}$. Particle formation was found to increase at a relative humidity of approximately $20 \%$ and higher. Variations in the initial number of particles present did not appear to have a significant effect on the particle formation, suggesting that nucleation was not a controlling factor under these conditions. However, tests in a commercial environment at much lower VOC concentrations and lower UV fluence rates showed no detectable PM2.5 formation, indicating that SOA formation during the intermittent use of germicidal UV may not significantly affect indoor air quality under normal conditions.
\end{abstract}

Keywords: fine particulate; PM2.5; UV disinfection; indoor air quality; toluene

\section{Introduction}

Ultraviolet (UV) light is increasingly used in residential, commercial, and institutional settings for the reduction of viable surface and airborne bacteria, spores, and viruses, and uses a mercury lamp with a wavelength of $254 \mathrm{~nm}$ to induce damage to the DNA in these targets. For example, automated UV disinfection has shown good effects in hospitals for reducing environmental biological burdens [1] and infection rates for susceptible patients [2].

However, it is well-known from atmospheric chemistry that longer wavelength solar UV (wavelengths from 300 to $400 \mathrm{~nm}$ ) can promote the generation of aerosol particles [3]. These aerosols are initiated by the UV-photo-oxidation of volatile organic compounds (VOCs) in the atmosphere, which eventually results in less volatile partial oxidation products. The products tend to condense, possibly onto other nano-particulates, and this results in the growth of new or larger aerosol particles, commonly referred to as secondary organic aerosols (SOA). The degree to which any specific oxidation product contributes to SOA formation depends on the equilibrium established between the gas and particle phases for that compound under the given conditions [4]. 
An example of photochemical SOA formation can be found in studies with toluene, a common indoor and urban atmospheric contaminant. Exposure to UV light initiates a sequence of reactions with oxygen and $\mathrm{OH}, \mathrm{HO}_{2}$ and other radical species to form organic peroxy radicals and eventually a range of phenolic and other semi-volatile and condensable species [5]. Semi-volatiles may self-nucleate to form particles [6] if the concentration is above the saturation point. However, if there is some other particulate mass present, the semi-volatiles may also partition into this phase, even at concentrations below the saturation point [7]. This pre-existing particulate, or "seed particles", will normally be present in indoor air and this mechanism of SOA growth will be present even under conditions where the VOC concentration is relatively low, where semi-volatile self-nucleation and particle growth is less likely.

A concern with SOA formation arises because fine particulate (PM2.5 or particulate matter with a diameter less than $2.5 \mu \mathrm{m}$ ) is strongly associated with negative health effects such as respiratory and cardiac disease [8]. Thus, these SOA particles may add to the background burden of PM2.5 in the atmosphere, and especially in indoor environments where germicidal UV devices are used.

Most work on SOA formation has been concerned with atmospheric chemistry and solar UV wavelengths (300-400 nm), but for indoor air quality purposes, germicidal UV ( $254 \mathrm{~nm}$ ) is more relevant for those situations where it may be applied for disinfection. Therefore, the first objective of this work was to determine if the shorter wavelength germicidal UV was similarly capable of generating SOA, and how the conditions might affect the extent of this SOA formation. Toluene was chosen as a target compound, in part because it has relatively strong absorption at $254 \mathrm{~nm}$, making it more susceptible to direct UV photo-oxidation. The potential impact of UV on particulate concentrations in a room undergoing automated disinfection was also assessed to determine if this may present a measurable indoor air quality concern for the use of these devices under the actual conditions found in a commercial environment.

\section{Materials and Methods}

A diagram of the experimental setup used for this project is shown in Figure 1. The system setup consisted of a custom-built UV reactor vessel, containing a UV lamp running the length of the reactor. The air in the system was recirculated using a Cole Parmer Masterflex peristaltic pump, with $60 \mathrm{~cm}$ of Masterflex size 17 Norprene tubing with a $6.4 \mathrm{~mm}$ inner diameter. The rest of the tubing used for recirculation was $370 \mathrm{~cm}$ of $0.935 \mathrm{~cm}$ (inner diameter) polytetrafluoroethylene (PTFE) tubing. The recirculation rate of the system gas was $415 \mathrm{~mL} / \mathrm{min}$, which is equivalent to one vessel air exchange every $63.5 \mathrm{~min}$. For the majority of the experiments, the air supplied to the UV reactor was compressed air from the building's system and was passed through an activated carbon/HEPA (high efficiency particulate air) filter PureFlo SKL Capsule (Saint-Gobain, Gaithersburg, MD, USA). This ensured that the air was relatively dry with a relative humidity of around $11 \%$, with the filtration removing most particles larger than $0.3 \mu \mathrm{m}$ diameter. In addition, some experiments were carried out with unfiltered compressed air, as well as with filtered and unfiltered room air with a relative humidity greater than $11 \%$.

The UV reactor vessel was a cylindrical stainless-steel vessel with an inner diameter of $20.3 \mathrm{~cm}$, and a length of $81.3 \mathrm{~cm}$, which had an effective volume of 26,359 mL. The UV lamp was a Sterilight model S8RL/4P (Viqua, Guelph, ON, Canada), a $40 \mathrm{~W}$ lamp that produced monochromatic UV light with a wavelength of $254 \mathrm{~nm}$, situated down the center axis of the reactor. The reactor vessel was operated at a room temperature of approximately $23{ }^{\circ} \mathrm{C}$ and monitoring of the recirculating gas temperature confirmed that a temperature rise of much less than $0.5^{\circ} \mathrm{C}$ occurred during UV exposure periods of $15 \mathrm{~min}$ and less. 


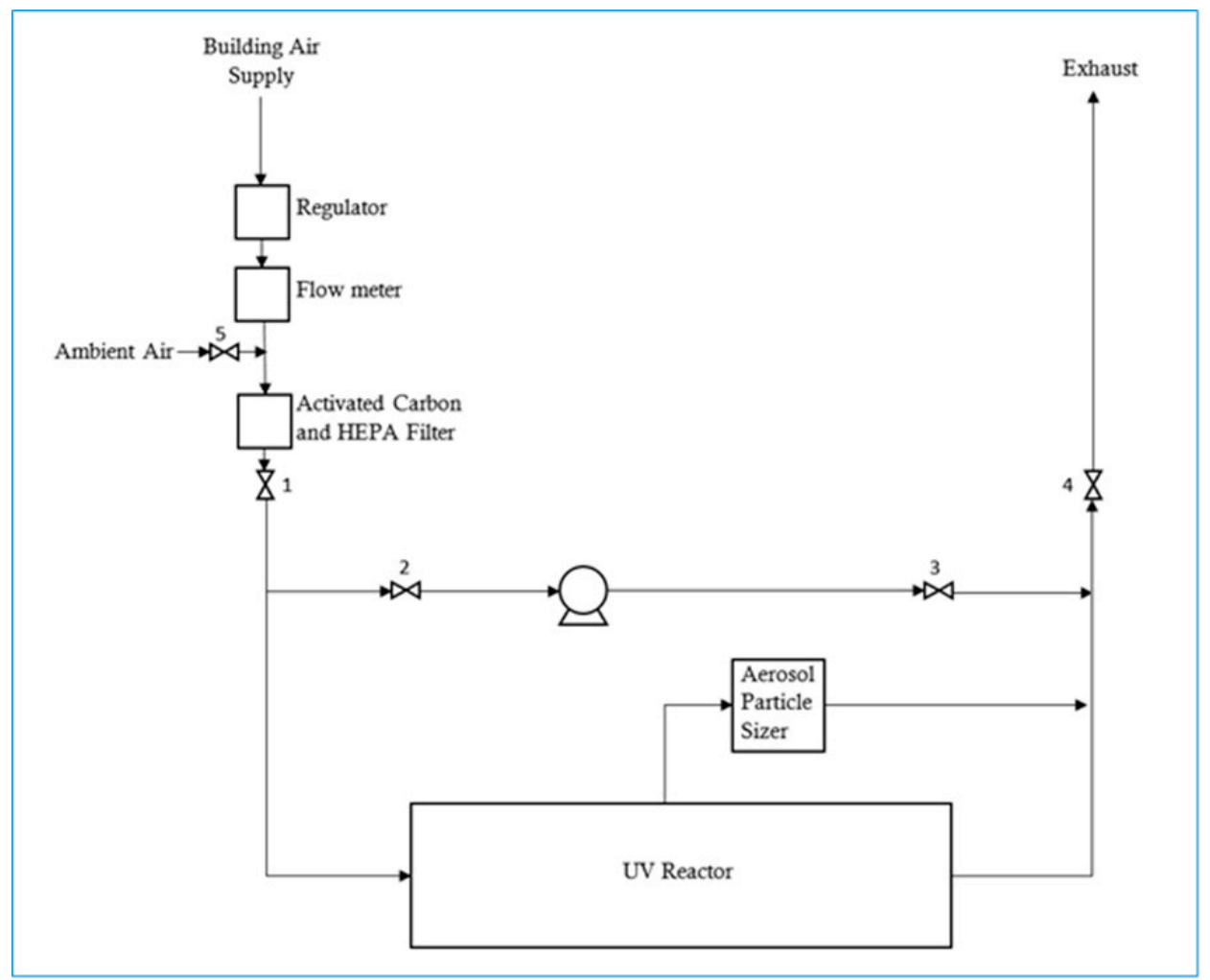

Figure 1. Schematic of the experimental apparatus used to generate secondary organic aerosols (SOA) by ultraviolet (UV) exposure.

Gas chromatography (GC) was used to monitor the toluene concentrations at the start and end of the experiment, using an HP 5890 Series II (Agilent Technologies Canada, Mississauga, Canada), with a Restek model Rtx-5 10240 (Chromatographic Specialties, Brockville, ON, Canada) fused silica column with an inner diameter of $0.53 \mathrm{~mm}$ and a length of $30 \mathrm{~m}$. Toluene was supplied by VWR International (Mississauga, ON, Canada) with a minimum purity of $99.5 \%$.

A TSI Aerosol Particle Sizer (APS) model 3321 (Shoreview, MN, USA) was used to monitor the number of aerosol particles present in the system by sampling directly from the UV reactor vessel, as shown in Figure 1. The APS was able to detect particles $0.5-20 \mu \mathrm{m}$ in diameter and these particles were sorted into 52 size fractions for size distribution analysis, as well as a fraction between 0.3 to $0.5 \mu \mathrm{m}$ which was aggregated as a size fraction of $<0.523 \mu \mathrm{m}$. Samples from the UV reactor were drawn through $86 \mathrm{~cm}$ of conductive silicon tubing (inner diameter of $11.2 \mathrm{~mm}$ ) manufactured by TSI for use with the APS.

\section{Results}

Initial blank controls with the UV light turned off confirmed that the presence or absence of toluene in the photoreactor had no detectable effect on particle formation over the period of an hour. Next, using toluene at an initial concentration ranging from 55 to $85 \mathrm{mg} / \mathrm{m}^{3}$, the effect of UV dose on particulate formation was assessed by running experiments for varying lengths of time with the UV lamp on, followed by a constant hold and recirculation time of $5 \mathrm{~min}$. The results are shown in Figure 2, where PM2.5 formation is the difference between initial particulate counts and those at the end of the experiment. It was observed that in the experimental setup, no statistically significant particulate formation was detectable until at least $5 \mathrm{~min}$ of UV exposure was used, and that the counts increased in an apparently non-linear manner beyond the 5 min exposure time. GC analysis confirmed that the toluene concentration in the gas phase significantly decreased over the course of each experiment for exposure times of $5 \mathrm{~min}$ or greater. The average disappearance of toluene from the gas phase was 
approximately $12 \%$ under these conditions, although there was no consistent trend detectable with UV exposure. No other VOCs were detected under the GC analysis conditions used in these experiments.

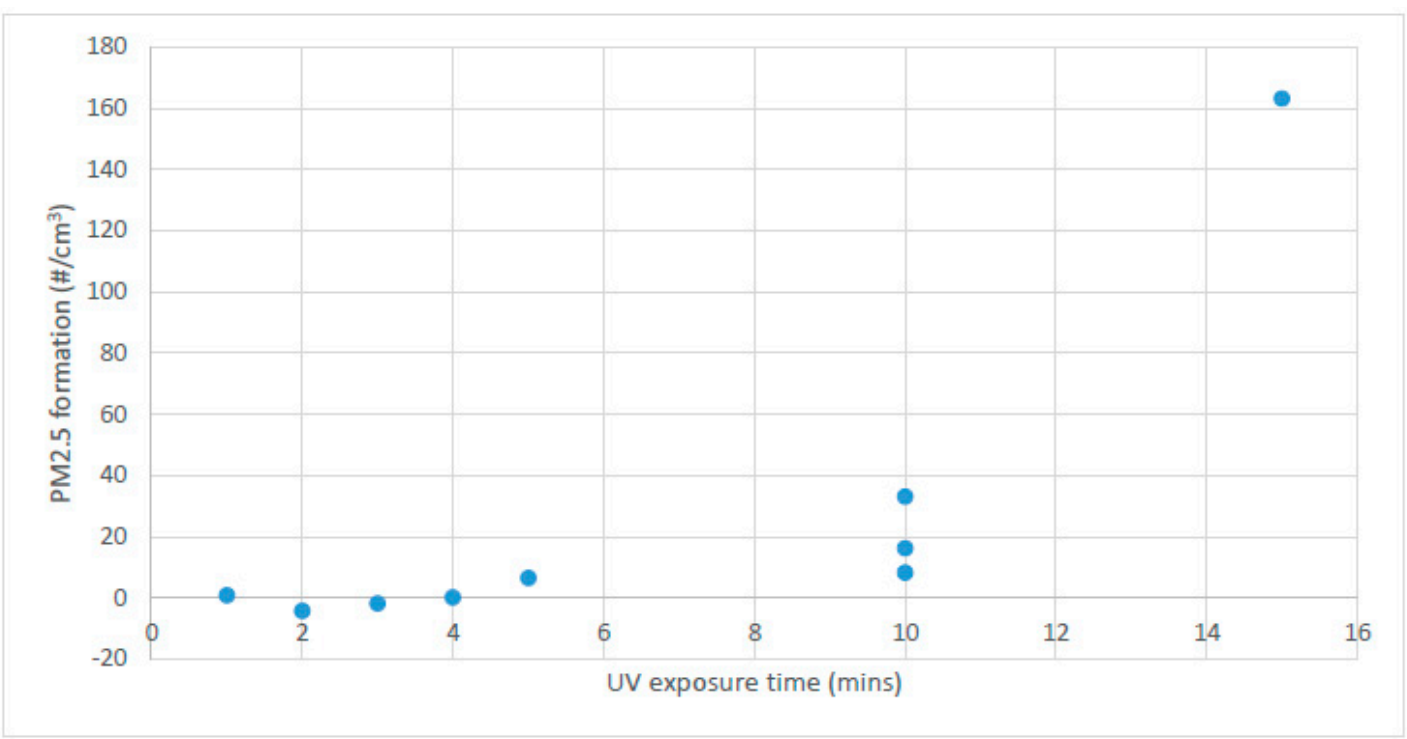

Figure 2. Fine particulate matter (PM2.5) formation (corrected for initial background counts) as a function of UV exposure time, with a constant recirculation time of $5 \mathrm{~min}$ after UV exposure, for initial toluene concentrations in air of 55 to $85 \mathrm{mg} / \mathrm{m}^{3}$. Triplicate experimental results are shown for $10 \mathrm{~min}$.

For the automated UV room disinfection units of interest, the typical exposure time was set for $5 \mathrm{~min}$ as this is generally found to provide a satisfactory disinfection dose [1]. Therefore, focusing on the $5 \mathrm{~min}$ of UV exposure, further experiments were performed to assess the particle size distribution within the range measurable by the TSI instrumentation, with the results shown in Figure 3. These results indicated that: (1) the injection of the toluene did not create particulate on its own (comparing air blank to air blank with toluene), and (2) most of the detectable particulate generation occurred at sizes less than $1 \mu \mathrm{m}$.

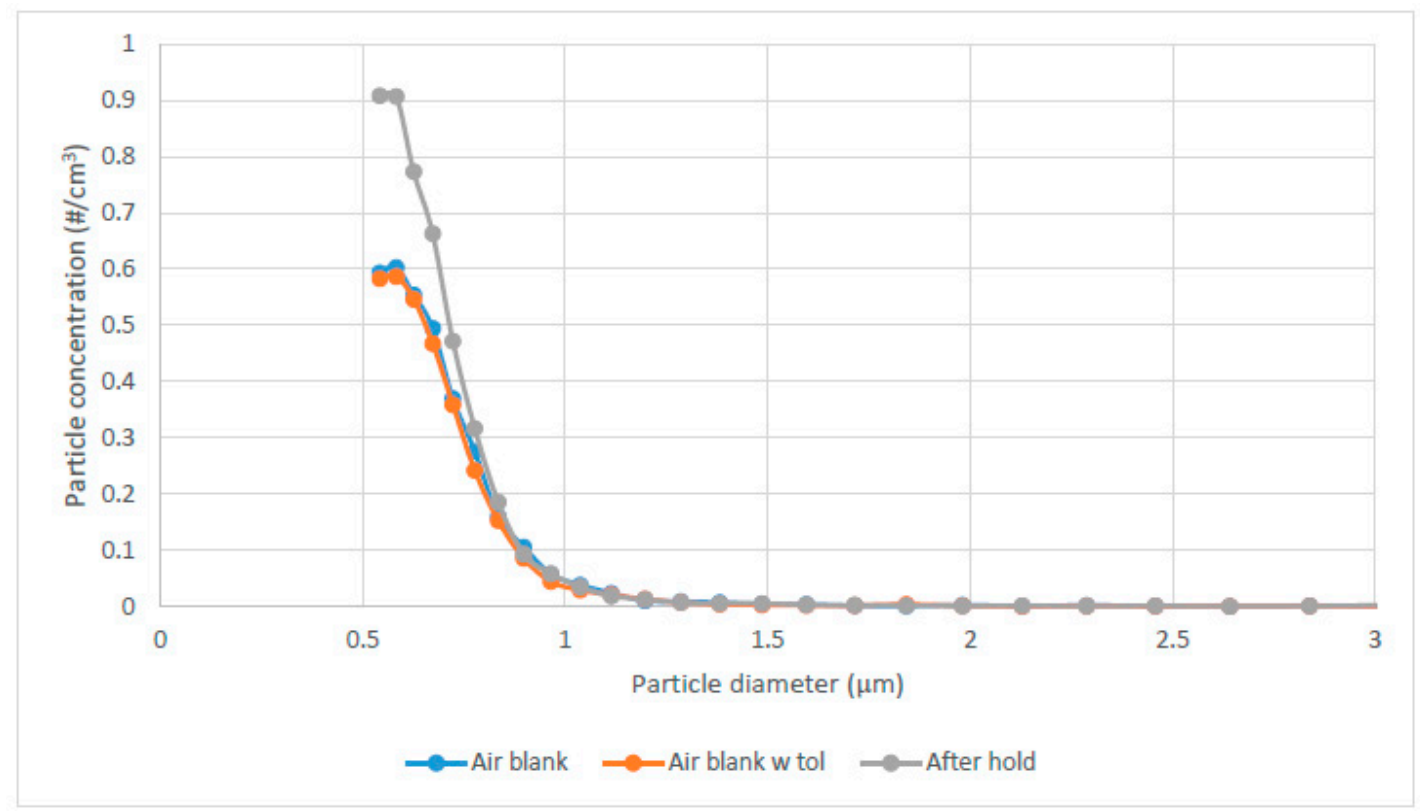

Figure 3. Particle size distribution for $5 \mathrm{~min}$ of UV exposure followed by $5 \mathrm{~min}$ of recirculation (hold) post-UV. 
It was expected that the UV exposure would initiate particulate formation by creating less volatile partial oxidation products of toluene, and that particulate growth would then play a role that would be related to total residence time. To test for this effect, a constant residence time of 6 minutes was used, with varying UV exposure times up to $5 \mathrm{~min}$ (the typical UV disinfection unit dose time). The results are shown in Figure 4, which re-confirms the results in Figure 2 whereby at least 5 min of UV dose were required for measurable particulate formation. It was concluded that under these experimental conditions, the effect of the hold time after UV exposure was not a significant factor in particulate counts. The particle size distribution for 5 min exposure time in Figure 4 was similar to that shown in Figure 3 (therefore not shown again), also indicating that UV exposure time played a more significant role than the total time available for particulate generation and growth. A $3^{3}$-factorial design with ANOVA analysis further confirmed that the initial toluene concentration and UV exposure time were the most significant factors in SOA particle formation counts [9].

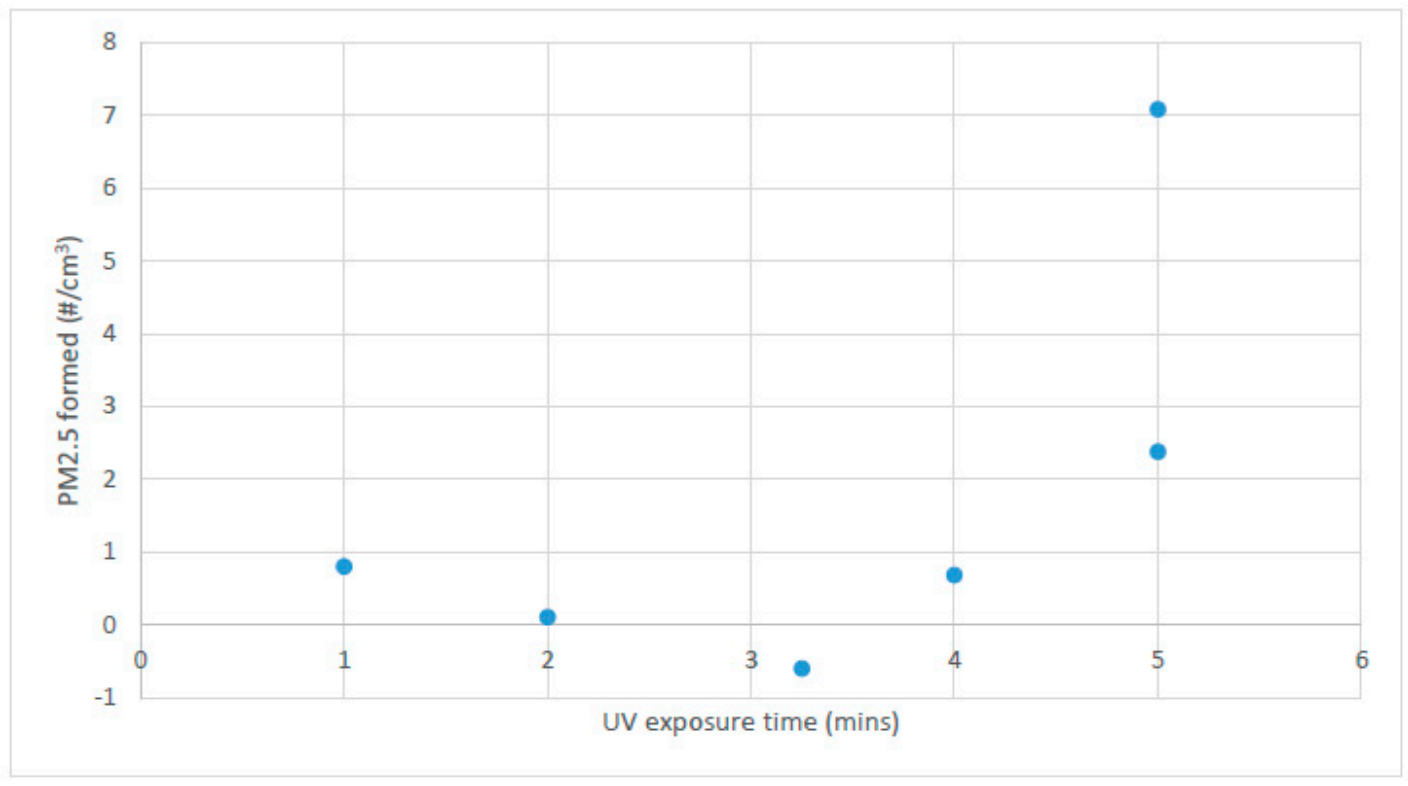

Figure 4. PM2.5 counts after a constant total time (6 $\mathrm{min})$, with varying UV exposure times and duplicate experiments at $5 \mathrm{~min}$.

The potential role of nucleation sites on SOA generation and growth was assessed by comparing the UV-induced SOA formation with air that was either initially HEPA filtered or not. The HEPA filtered air contained approximately $5 \times 10^{6}$ particles $/ \mathrm{m}^{3}$ as measured by the APS instrument after the injection of toluene to a concentration of $58 \mathrm{mg} / \mathrm{m}^{3}$, while the unfiltered air contained approximately $10 \times 10^{6}$ particles $/ \mathrm{cm}^{3}$ under the same initial conditions. After $5 \mathrm{~min}$ of UV exposure and $1 \mathrm{~min}$ of recirculation, the change in particulate concentration was measured, as displayed in Figure 5. There was some indication that filtered air tended to produce smaller particle sizes under similar UV exposure conditions, however the difference was not significant based on a statistical analysis of the total particle counts. This suggests that nucleation sites did not play a large role in SOA formation, at least under the conditions used in these experiments, although it is possible that the size distributions tend towards smaller particles when there are fewer particles initially present in the filtered air.

The foregoing results were obtained using compressed plant air with a low relative humidity of approximately $11 \%$ at room temperature. To explore the role of water in SOA formation, further experiments were conducted with room air that varied in relative humidity from day to day. The air was drawn into the UV reactor using an air sampling pump, and was either HEPA filtered or not to further examine the effects of nucleation sites for SOA growth. For constant initial toluene concentrations and UV exposure times, the number of particles produced was measured by comparing particle counts before and after UV, with the results summarized in Figure 6. 


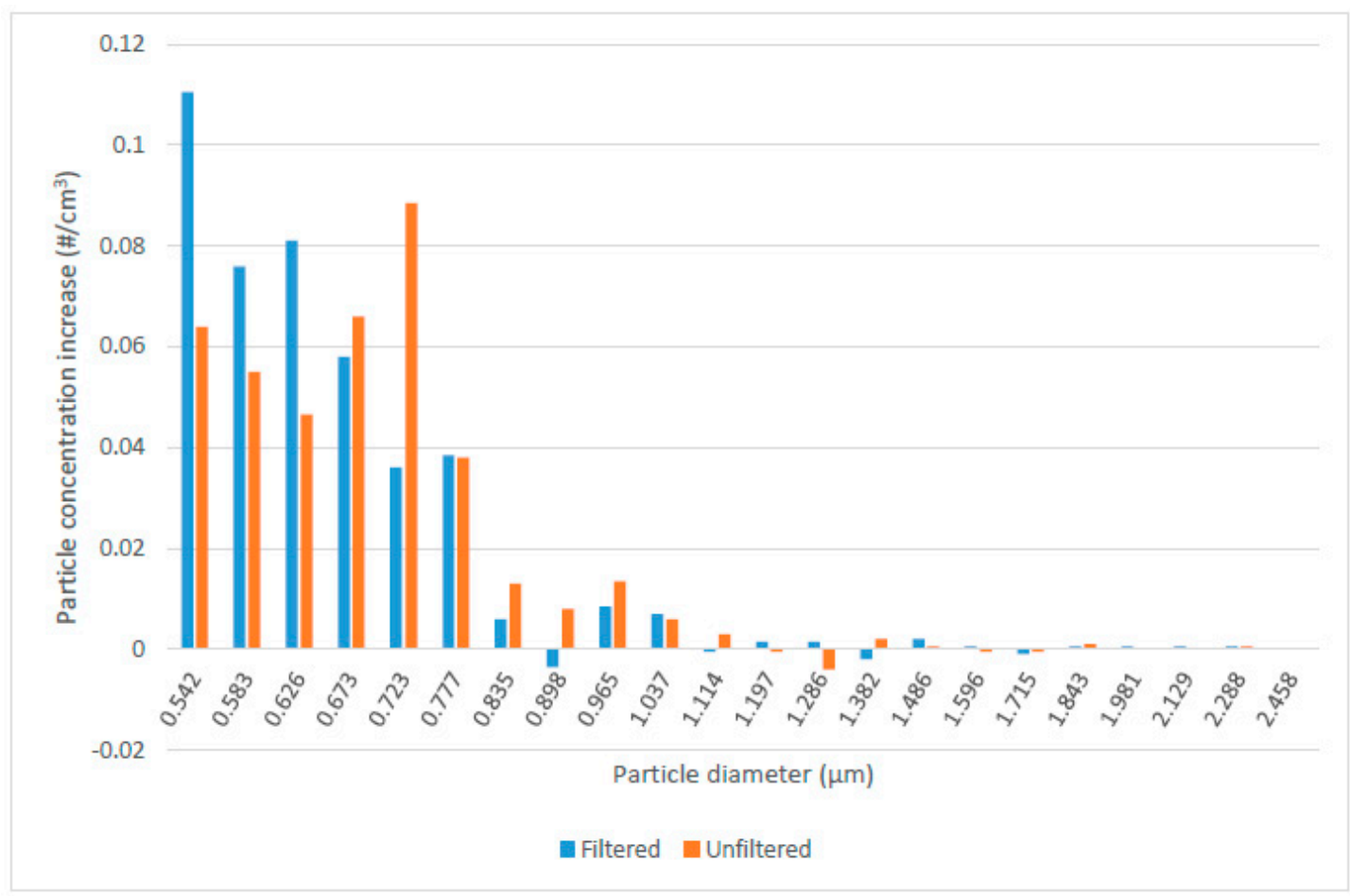

Figure 5. Effect of HEPA filtered versus unfiltered compressed air on generation of particulate at various sizes with $5 \mathrm{~min}$ of UV exposure and $1 \mathrm{~min}$ of recirculation (initial toluene concentrations 55 to $\left.85 \mathrm{mg} / \mathrm{m}^{3}\right)$.

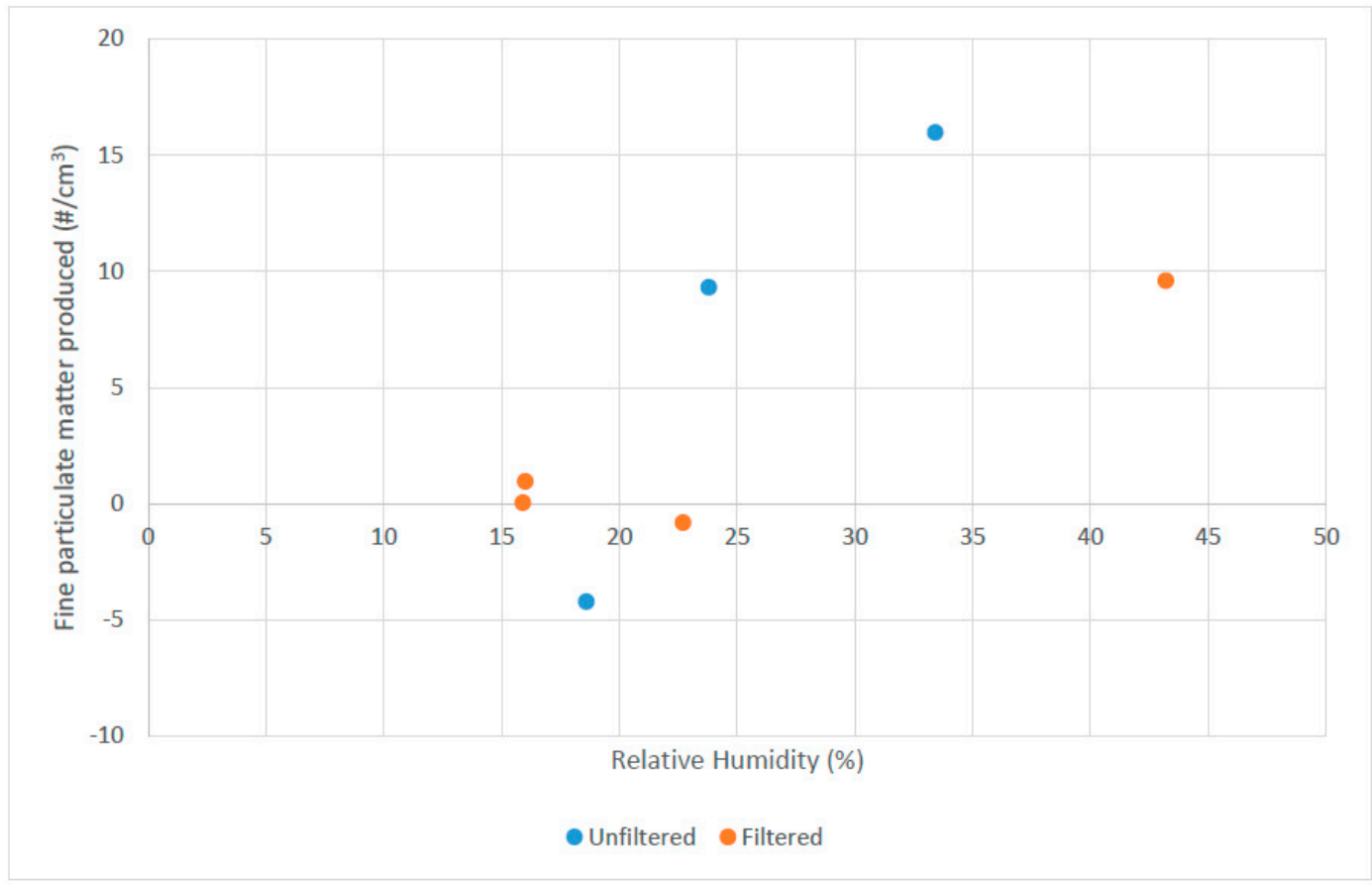

Figure 6. PM2.5 production for filtered and unfiltered room air at different relative humidities. Initial toluene concentration was between 55 and $85 \mathrm{mg} / \mathrm{m}^{3}$, with $5 \mathrm{~min}$ of UV exposure and $1 \mathrm{~min}$ of hold time before sampling. The initial particulate counts for unfiltered and filtered air were approximately $43 \times 10^{6}$ and $5 \times 10^{6}$ particles $/ \mathrm{m}^{3}$, respectively.

As indicated in Figure 6, the particle formation was relatively low for low humidities, similar to the results shown in Figure 2, where compressed air was used as the medium with approximately $11 \%$ 
relative humidity. However, as the humidity approached and exceeded $25 \%$, there appeared to be a discrete jump in particulate formation. The chemistry of SOA formation from toluene and similar compounds is quite complex [4] and water vapor or aerosol plays a role in the yield of SOA under solar UV wavelengths [10]. The results in Figure 6 indicate that SOA formation with germicidal UV will be somewhat higher at typical indoor air humidity levels (30 to $45 \%$ ) compared to drier air. As noted by $\mathrm{Ng}$ et al. [8], quantifying SOA mass yields is a very challenging experimental problem, and this was not attempted in this work. However, the trends shown here are consistent with results from previous research using solar UV wavelengths.

As indicated in the UV reactor experiments, SOA formation appeared to be possible and measurable under exposure times that might be expected in a room UV disinfection cycle, although the impact was relatively small. However, the question of whether measurable SOA is created in a typical room during UV disinfection does not appear to be answered in the literature. Therefore, as a quick screening method to test for this SOA formation under more representative and realistic room disinfection conditions, particle sampling was undertaken in a bathroom that had been fitted with an automated UV disinfection device previously described by Hunt and Anderson [1]. The APS instrument was used to take samples before, during and after UV disinfection in the bathroom, with the results shown in Figure 7.

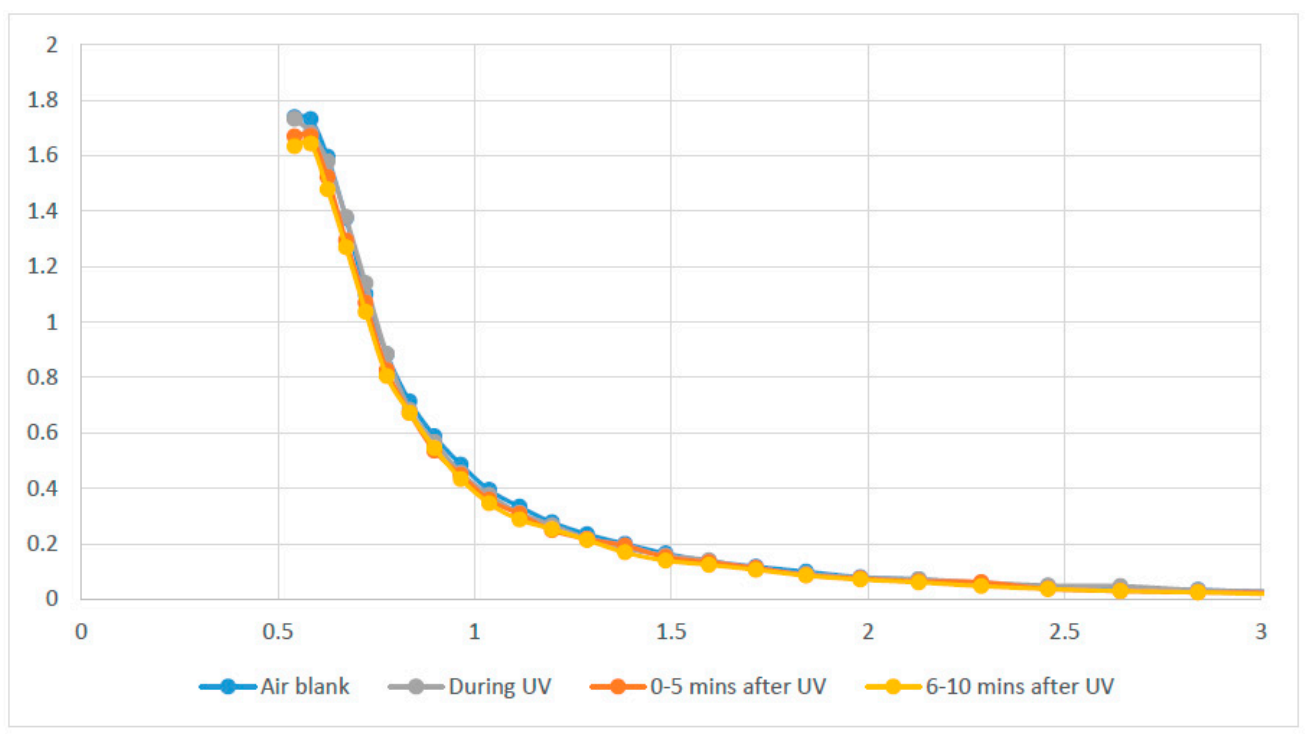

Figure 7. Particulate size distribution (particulate counts per $\mathrm{cm}^{3}$ versus particle diameter in $\mu \mathrm{m}$ ) in a bathroom with an above-door automated UV system, before (air blank), during and after an automated 5 mins UV disinfection cycle. Most points are collinear and superimposed.

The air in the room was like that found in a typical commercial office building, with no noticeable odor and relatively low initial particle counts $\left(33 \times 10^{6}\right.$ particles $\left./ \mathrm{m}^{3}\right)$. Although it was not feasible to measure the volatile organic compound concentrations, the literature reports that such office environments typically have a sum of common VOC concentrations ranging from 64 to $76 \mu \mathrm{g} / \mathrm{m}^{3}$ [11]. As can be seen in Figure 7, under the tested conditions there was no significant change in either the numbers or size distribution of particulates in the room during or after a disinfection cycle.

\section{Discussion}

Although the UV reactor experiments indicated that some SOA formation is possible or likely, the conditions in these experiments have several important differences from those found in the room environment where UV disinfection was used. First, the concentrations of VOC (toluene) were around 50 to $85 \mathrm{mg} / \mathrm{m}^{3}$, which is up to three orders of magnitude higher than VOC concentrations typically found in commercial and institutional environments [12]. Secondly, the average UV fluence rate within 
the reactor was relatively high $\left(19.5 \mathrm{~mW} / \mathrm{cm}^{2}\right)$ compared to the wide range of fluence rates that will be found in a room, depending on the distance to the UV lamps. For this room, the average fluence rate was very roughly estimated to be approximately $0.14 \mathrm{~mW} / \mathrm{cm}^{2}$ using a simplified geometrical technique for annular photoreactors reported by Bolton [13]. This mean fluence rate estimate is consistent with the measured values on surfaces in a similar room, reported to range from 0.01 to $0.1 \mathrm{~mW} / \mathrm{cm}^{2}$ depending on the distance from the UV lamp to the surface in the room [1]. Unfortunately, it was not feasible to replicate the lower fluence rate bathroom conditions within the photoreactor due to equipment limitations.

It can be observed from this work that germicidal UV disinfection devices operating at $254 \mathrm{~nm}$ are capable of generating SOA in ways that follow the trends identified in atmospheric chemistry for solar UV wavelengths (300 to $400 \mathrm{~nm}$ ). Presumably the mechanisms will be similar, with photo-oxidation causing the formation of partially oxidized toluene by-products with lower vapor pressure, which then partition or condense to form new or larger particulates in the gas phase. This mechanism will depend to some extent on the nature of the VOC, its UV absorption spectrum, its oxidation pathway and the vapor pressure and partitioning behavior of the oxidation products. Therefore, it would be worthwhile to examine the behavior of other VOCs under UV germicidal wavelengths. However, based on the preliminary tests performed in a room, the practical impact on PM2.5 concentrations for realistic situations in commercial and institutional spaces is possibly minimal, especially compared to other internal and external sources of fine particulate that may impact the air quality in these rooms. Further measurements of actual room air particulate counts before and after UV disinfection in a wide variety of locations would be useful to confirm these preliminary observations.

\section{Conclusions}

Fine particulate matter (PM2.5) is generated by the action of germicidal UV radiation $(254 \mathrm{~nm})$ on a target volatile organic compound (toluene) in air. This suggests that the mechanisms reported for secondary organic aerosol (SOA) formation via solar UV wavelengths (300-400 nm) in the atmosphere may be applicable to indoor air quality where germicidal UV systems are used. In a laboratory photoreactor with relatively high toluene concentrations in air, PM2.5 formation was enhanced by longer UV exposure times and higher humidities. However, in a more realistic test in a commercial bathroom no measurable PM2.5 was found. The impact of germicidal UV on indoor air SOA concentrations needs further work under varying conditions, but initial indications suggest that it is not a large impact.

Author Contributions: Conceptualization, W.A.A.; Formal analysis, E.C.; Funding acquisition, W.A.A.; Investigation, E.C.; Methodology, E.C. and Z.T.; Resources, Z.T.; Supervision, W.A.A. and Z.T.; Writing-original draft, E.C.; Writing-review and editing, W.A.A..

Funding: This research was funded by the Natural Sciences and Engineering Research Council of Canada under the Discovery Grant program.

Acknowledgments: The assistance of Carol Moralejo with gas chromatography is gratefully acknowledged, and Class 1 Inc. (Cambridge, ON, Canada) provided access to a room with a UV disinfection device.

Conflicts of Interest: The authors declare no conflict of interest, and the funders and Class 1 Inc. had no role in the design of the study; in the collection, analyses, or interpretation of data; in the writing of the manuscript, or in the decision to publish the results.

\section{References}

1. Hunt, B.; Anderson, W.A. Reduction of Hospital Environmental Contamination Using Automatic UV Room Disinfection. Available online: http:/ /infectioncontrol.tips/2016/08/21/reduction-hai-using-uv-818/ (accessed on 26 November 2018).

2. Nagaraja, A.; Visintainer, P.; Haas, J.P.; Menz, J.; Wormser, G.P.; Montecalvo, M.A. Clostridium difficile infections before and during use of ultraviolet disinfection. Am. J. Infect. Control 2015, 43, 940-945. [CrossRef] [PubMed] 
3. Kroll, J.H.; Ng, N.L.; Murphy, S.M.; Flagan, R.C.; Seinfeld, J.H. Secondary organic aerosol formation from isoprene photooxidation. Environ. Sci. Technol. 2006, 40, 1869-1877. [CrossRef] [PubMed]

4. Kroll, J.H.; Seinfeld, J.H. Chemistry of secondary organic aerosol: Formation and evolution of low-volatility organics in the atmosphere. Atmos. Environ. 2008, 42, 3593-3624. [CrossRef]

5. Ng, N.L.; Kroll, J.H.; Chan, A.W.H.; Chhabra, P.S.; Flagan, R.C.; Seinfeld, J.H. Secondary organic aerosol formation from $m$-xylene, toluene, and benzene. Atmos. Chem. Phys. 2007, 7, 3909-3922. [CrossRef]

6. Huang, M.; Zhang, W.; Hao, L.; Wang, Z.; Zhou, L.; Gu, X.; Fang, L. Chemical Composition and Reaction Mechanisms for Secondary Organic Aerosol from Photooxidation of Toluene. J. Chin. Chem. Soc. 2006, 53, 1149-1156. [CrossRef]

7. Hallquist, M.; Wenger, J.C.; Baltensperger, U.; Rudich, Y.; Simpson, D.; Claeys, M.; Dommen, J.; Donahue, N.M.; George, C.; Goldstein, A.H.; et al. The formation, properties and impact of secondary organic aerosol: Current and emerging issues. Atmos. Chem. Phys. 2009, 9, 5155-5236. [CrossRef]

8. Feng, S.; Gao, D.; Liao, F.; Zhou, F.; Wang, X. The health effects of ambient PM2.5 and potential mechanisms. Ecotox. Environ. Safe. 2016, 128, 67-74. [CrossRef] [PubMed]

9. Choi, E. The Role of Germicidal Ultraviolet Light in the Formation of Secondary Organic Aerosols. Master's Thesis, University of Waterloo, Waterloo, ON, Canada, 2017.

10. Hildebrandt, L.; Donahue, N.M.; Pandis, S.N. High formation of secondary organic aerosol from the photo-oxidation of toluene. Atmos. Chem. Phys. 2009, 9, 2973-2986. [CrossRef]

11. Mandin, C.; Trantallidi, M.; Cattaneo, A.; Canha, N.; Mihucz, V.G.; Szigeti, T.; Mabilia, R.; Perreca, E.; Spinazzè, A.; Fossati, S.; et al. Assessment of indoor air quality in office buildings across Europe-The OFFICAIR study. Sci. Total Environ. 2017, 579, 169-178. [CrossRef] [PubMed]

12. Brown, S.K.; Sim, M.R.; Abramson, M.J.; Gray, C.N. Concentrations of volatile organic compounds in indoor air-A review. Indoor Air 1994, 4, 123-134. [CrossRef]

13. Bolton, J.R. Calculation of ultraviolet fluence rate distributions in an annular reactor: Significance of refraction and reflection. Water Res. 2000, 34, 3315-3324. [CrossRef] 